2016-06

\title{
'Child friendly' international human rights standards and youth offending team partnerships
}

\author{
Gray, Patricia
}

http://hdl.handle.net/10026.1/5213

10.1016/j.jjlcj.2015.11.001

International Journal of Law, Crime and Justice

Elsevier

All content in PEARL is protected by copyright law. Author manuscripts are made available in accordance with publisher policies. Please cite only the published version using the details provided on the item record or document. In the absence of an open licence (e.g. Creative Commons), permissions for further reuse of content should be sought from the publisher or author. 
"This is a final author's draft of a paper submitted for publication in International Journal of Law, Crime and Justice 2016 DOI:

http://dx.doi.org/10.1016/j.ijlcj.2015.11.001

\title{
'Child friendly' international human rights standards and youth offending team partnerships
}

\author{
Patricia Gray* \\ School of Law, Plymouth University, Drake Circus, Plymouth PL4 8AA, UK.
}

\begin{abstract}
International human rights standards stipulate that youth justice should be 'child friendly' and protect the 'best interests' or welfare of young people who offend. The multi-agency composition of youth offending teams (YOTs) in England and Wales seems to offer the ideal arrangement to achieve these standards. Yet while official inspections generally praise YOTs highly for reducing the risk of reoffending, independent research reveal significant shortfalls in their work to address the social welfare difficulties of young people who offend. This article uses an empirical study of YOT partnerships to explore why young people's social welfare needs are not being met. It challenges explanations which blame the audit culture and public spending cuts, and argues that such failure stems from the way young people's social welfare problems are framed. The article ends on a positive note by considering how a rights-based approach could be used to uphold young people's social rights.
\end{abstract}

Keywords: International human rights; Social welfare; Audit culture; Dematerialisation of need; Rights-based approach

*Corresponding author. Tel.: +44 01752585 782. E-mail address: P.Gray@plymouth.ac.uk 
"This is a final author's draft of a paper submitted for publication in International Journal of Law, Crime and Justice 2016 DOI:

http://dx.doi.org/10.1016/j.ijlcj.2015.11.001

\section{Introduction}

International human rights standards set out an explicit message that youth justice systems should be 'child friendly' and protect the 'best interests' or welfare of children in conflict with the law (Kilkelly, 2011; Moore, 2013), who, research repeatedly inform us, have experienced high levels of socio-economic disadvantage (Jacobson et al., 2010). Article 3 of the 1989 United Nations Convention on the Rights of the Child (UNCRC), which the United Kingdom ratified in 1991, states that the latter principle should be 'paramount' in youth justice, and in the European context guidelines for 'child friendly justice' were formally adopted by the Council of Europe in 2010.

Throughout the $20^{\text {th }}$ century the pursuit of these standards has influenced the development of youth justice policy and practice in England and Wales. ${ }^{1}$ The first juvenile courts were established in 1908 with the somewhat ambiguous aim of providing 'for the rescue as well as the punishment of children' (cited in Parsloe, 1978: 139), but as the century progressed welfare principles were more explicitly spelt out in legislation such as the iconic 1933 and 1969 Children and Young Person Acts (Parsloe, 1978). The efforts to integrate welfare considerations into youth justice proceedings have continued into the $21^{\text {st }}$ century. While the 1998 Crime and Disorder Act effected significant changes to the delivery of youth justice for children between the ages of 10 and 18 years by creating multi-agency Youth Offending Teams (YOTs) made up of representatives from probation, education, health, children's services and the police, its initial aim was simply to prevent offending amongst young people by addressing the risk factors (National Audit Office, 2010). However, as the heightened welfare focus of the 'every child matters' agenda (Department for Education, 2003) and of the 1989 and 2004 Children Acts (Muncie, 2015) has been progressively translated into youth justice (HM Government, 2008), these teams have been given the more specific remit of preventing offending by forming partnerships with a variety of social service providers to offer young people 'holistic', 'childfriendly' support to sort out the welfare problems which were seen to place them 'at risk' (Centre for Social Justice, 2012). The recommendations of the Munro Review in relation to child protection has further emphasised a 'child-centred' approach to youth justice (Department for Education, 2011).

\footnotetext{
${ }^{1}$ The age range and title of juvenile/youth courts have substantially varied during this period (see Parsloe, 1978).
} 
"This is a final author's draft of a paper submitted for publication in International Journal of Law, Crime and Justice 2016 DOI:

http://dx.doi.org/10.1016/j.ijlcj.2015.11.001

Unfortunately, this apparent commitment to protecting the child's 'best interests' or welfare through the provision of 'child friendly' youth justice measures has not led to improved welfare outcomes for young people who offend. YOTs are subject to regular inspection and in recently completed inspections they have generally received high praise ${ }^{2}$ for the quality of their work to safeguard young people and reduce their risk of offending and harm to others (Criminal Justice Joint Inspection, 2013). Partnership work has also scored highly in these inspections, with the thematic inspection of offending behaviour, health and education, training and employment noting that in all the YOTs visited 'partnership work was a key strength'(Criminal Justice Joint Inspection, 2011: 41). But inspections provide a distorted picture of success because they focus on 'processes' rather than 'outcomes', and when they do measure outcomes these are mainly centred around reducing the risk of reoffending rather than alleviating young people's social welfare difficulties (Centre for Social Justice, 2012).

Independent research reveals a more negative picture than the inspections, providing powerful evidence that YOTs, in partnership with children's and other social services, often fail to resolve the complex family, education, employment, emotional and mental health needs of young people who offend (Soloman and Garside, 2008; Centre for Social Justice, 2012; House of Commons Justice Committee, 2013; Carlile, 2014). As long ago as 2008 the Committee on the Rights of the Child (CRC, 2008: 7), which monitors the implementation of the 1989 UNCRC, condemned the UK for its failure 'to ensure that the principle of the best interests of the child... is adequately integrated in all legislation and policies' impacting on young people in conflict with the law. ${ }^{3}$ It would seem that little has changed in terms of protecting their 'best interests' by addressing welfare issues since this criticism was made.

On the surface YOT partnerships appear to provide the perfect vehicle to coordinate and deliver interventions which meet the welfare needs of young people who offend. Yet the above research evidence suggests that the outcomes of these partnerships have fallen short of expectations. The remainder of this article sets out to explore some of the factors that might explain this shortfall.

\footnotetext{
${ }^{2}$ This contradicts the criticisms of YOT partnerships in the Criminal Justice Joint Inspection (2012) of 'Looked After Children'.

${ }^{3}$ This repeated the criticisms made in earlier reports and is likely to be further confirmed in the forthcoming CRC report (CRAE, 2014).
} 
"This is a final author's draft of a paper submitted for publication in International Journal of Law, Crime and Justice 2016 DOI:

http://dx.doi.org/10.1016/j.ijlcj.2015.11.001

\section{YOT partnerships at work: the audit and managerialist deluge}

Critics have attributed the failure of YOT partnerships to adequately address the welfare of young people who offend to a 'punitive turn', and the negative influence of an audit and performance management culture which adopts an actuarial style of reasoning to view youth crime as a risk to be scientifically assessed and managed (Muncie, 2011). This, they claim, has led to the replacement of 'welfarist', 'child-centred' youth justice policies with a correctionalist ethos of changing anti-social attitudes and behaviour as a way of reducing the risk of reoffending (Goldson, 2010). It is further contended that instead of encouraging collaborative working arrangements to address young people's welfare difficulties, this culture has created tensions between YOTs and their social service partners as they may have conflicting and contradictory targets (Souhami, 2009). The austerity measures of the Coalition government that took office in 2010 and cuts in public expenditure were also expected to exacerbate the situation and further widen the gap between 'welfarism' and 'correctionalism' (Hollingsworth, 2012).

The research which underpins this article therefore set out to question the tensions that arise in YOT partnerships and to consider the perceived impact of public spending cuts. ${ }^{4}$ No attempt was made to engage in a comprehensive explanation of all tensions. Instead the research focused on the tensions faced by YOT partnerships in addressing Levitas et al's.(2007) three indicators for measuring social disadvantage. ${ }^{5}$ The first indicator 'resources' pertains to income and the quality of family and other interpersonal support networks. 'Resource' tensions were explored through partnerships with children's services. The second indicator is 'participation' and has to do with engagement in education, training and employment (ETE). These tensions were investigated through partnerships with alternative education providers. 'Quality of Life' is the final indicator and covers emotional well-being and mental health. Tensions here were examined through partnerships with mental health agencies which at the time of the research were mainly run by the Child and Adolescent Mental Health Services (CAMHS).

Three sets of data were collected between spring 2011 and the end of 2012 (see Gray, 2013, for a detailed discussion of the research design). First, broad quantitative data was

\footnotetext{
${ }^{4}$ These cuts had only just started when this research began. Since 2010/11 there has been a more than 19\% reduction in YOT funding (Ministry of Justice, 2015) and since 2009 a $25 \%$ fall in the YOT workforce (Deloitte, 2015).

${ }^{5}$ These were originally developed to measure social exclusion but can equally be applied to assess levels of social disadvantage.
} 
"This is a final author's draft of a paper submitted for publication in International Journal of Law, Crime and Justice 2016 DOI:

http://dx.doi.org/10.1016/j.ijlcj.2015.11.001

collated from one hundred and fifty interviews with managers and practitioners from forty one (out of a then one hundred and fifty seven) YOTs about their partnership arrangements with a variety of social welfare providers. Second, thirty two in-depth, semi-structured qualitative interviews were held with a purposive sample of YOT managers and practitioners and their partners from children's, educational and mental health agencies. This sample was drawn from two different YOT catchment areas that were not part of the quantitative research. Finally, observational analysis was undertaken of multi-agency partnership forums in action where YOT staff and representatives from various social services met to assess and act upon young people's family, educational and mental health difficulties. This article draws upon a thematic analysis of the thirty two qualitative interviews which focused on how young people's problems were interpreted; tensions and compromises in YOT partnerships; constraints arising from public spending cuts; and balancing welfare, correctionalism and public protection.

The Coalition government's political agenda not only set out, as mentioned earlier, to cut public spending, it also sought to reduce the scope of centralized managerialist edicts by reducing the number of national targets and performance indicators and giving them a more local flavour (House of Commons Justice Committee, 2013). Nevertheless, during the research interviews with YOT partnership stakeholders ${ }^{6}$ it became evident that the trappings of the audit and performance management culture, in which targets, league tables and inspections were prominent features, continued to dominate their working environment. For some respondents this culture was viewed positively as the continual monitoring of targets and performance prompted improvements in service provision by pinpointing resource gaps and other deficiencies. Others spoke more neutrally of audit and performance management, viewing them as little more than 'box ticking exercises' (YOT partnership stakeholder 26). But for a substantial number of respondents it was, as one commented, a 'waste of time' which created 'lots of bureaucracy', 'hundreds of targets' and 'an industry in its own right' that severely curtailed their time spent helping young people (YOT partnership stakeholder 7).

\subsection{Resource tensions}

In general, as YOT practitioners talked in the interviews they portrayed themselves as astute and adept performers in this culture who were able to cope with the constraints. But they also

\footnotetext{
${ }^{6}$ This phrase is used generically to protect the identities of all YOT workers and their partners in social welfare agencies, whether practitioners or managers, who participated in this research.
} 
"This is a final author's draft of a paper submitted for publication in International Journal of Law, Crime and Justice 2016 DOI:

http://dx.doi.org/10.1016/j.ijlcj.2015.11.001

recognized that there were tensions, mainly of an operational nature, in their partnerships with other social service providers which significantly reduced the success of their interventions. The first set of tensions explored with interviewees was their partnerships with children's services, because these were seen to play a crucial role in strengthening young people's 'resources' or the quality of their family and other close interpersonal support networks. Both national research (Youth Justice Board, 2010) and this research found that one of the main sources of tensions in these partnerships were disputes over thresholds or eligibility criteria, which meant that young people who offend were not being effectively protected from harmful and abusive relationships. The 'Looked After Children' inspection was particularly scathing of the failure of YOTs and children services to safeguard this exceptionally vulnerable target group (Criminal Justice Joint Inspection, 2012). In the research interviews many YOT workers spoke of how children's services often set their eligibility criteria too high, making it difficult for young people to receive adequate support in dealing with problematic interpersonal relations. One worker described the dilemma with children's services as follows:

“... they're very busy, so they've got to gate keep and creating high thresholds is the way they do it...it creates a lot of tension because as a worker if you're holding what you see as a risky safeguarding case and children's services are not willing to take the case, you're shouldering that responsibility on your own and actually it should be a shared responsibility." (YOT partnership stakeholder 14)

Another source of tension with children's services was the common perception among YOT workers that the latter would 'pass the buck' (YOT partnership stakeholder 24) once they knew the YOT was involved with the expectation that the YOT would provide the necessary welfare support. One worker outlined this tension as follows:

“...there's a feeling that if a young person's got a court order and they're with the YOT, then because we're social workers we should take on all the welfare work as well, even though our remit is offending. We obviously do an element of welfare but the main welfare agency is children's services. Yet quite often they will put pressure on to close the case because the young person is with us." (YOT partnership stakeholder 21)

\subsection{Participation tensions}

According to research young people's 'participation' in education, training and employment (ETE) is a significant protective factor in reducing their risk of reoffending (Centre of Social 
"This is a final author's draft of a paper submitted for publication in International Journal of Law, Crime and Justice 2016 DOI:

http://dx.doi.org/10.1016/j.ijlcj.2015.11.001

Justice, 2012). The thematic inspection of ETE interventions (Criminal Justice Joint Inspection, 2011) identified two key tensions in partnerships between education providers and YOTs which inhibited the delivery of ETE support to young people, both of which were widely discussed in the interviews for this research. The first problem centred on concerns about the poor quality and limited choice of ETE provision, particularly alternative provision, and whether it was suitable for young offenders:

"...Good quality courses to equip them with qualifications have always been in short supply. Most have been designed to keep the unemployment figures down rather than provide anything meaningful." (YOT partnership stakeholder 30)

The second concern related to the perception that some education providers often rejected and 'othered' YOT young people beyond school age because of the 'baggage they brought with them' (YOT partnership stakeholder 23) or the fear that their chaotic lifestyles compromised their ability to complete programmes and so lowered success rates upon which funding was based:

"...colleges of further education are reluctant to take our children... because so many of these courses are paid by the number of children that complete the course and they see our kids as potentially disruptive and unlikely to finish. So if they're paid by the ones that complete why would they take ours? And the reality is they don't." (YOT partnership stakeholder 19)

\subsection{Quality of life tensions}

Several national research studies have criticized YOT partnerships for failing to address young people's 'quality of life' or emotional and mental health difficulties (Berelowitz, 2011; Care Quality Commission and HMI Probation, 2011). In this research the key tensions raised by interviewees in this area were over access and engagement because it was felt that their main mental health partner (i.e. CAMHS) rigidly maintained a somewhat clinical, fixed appointment style of delivery which made it inaccessible to most YOT young people, given their chaotic lifestyles. As one respondent commented:

"...YOT workers are very, very good at engaging 16 and 17 year olds and going out where they are, whether it's a café or a pub... their outreach skills are very finely tuned. Whereas, these guys (referring to CAMBS workers) operate to an outpatient booking 
"This is a final author's draft of a paper submitted for publication in International Journal of Law, Crime and Justice 2016 DOI:

http://dx.doi.org/10.1016/j.ijlcj.2015.11.001

system so if you are referred there and you're accepted because you meet the criteria, you are then offered an appointment to attend at a clinic in your area. Right, well a lot of the guys and girls that we're talking about don't operate like that so they haven't yet properly developed outreach services which are suitable for the sort of clients that the YOT and our drugs team see." (YOT partnership stakeholder 12)

As in partnerships with children services, thresholds were another source of contention as the complex emotional turmoil that most YOT young people faced in their daily lives did not 'fit neatly into boxes' (YOT partnership stakeholder 11) or conform to standard, diagnosable mental health conditions. Thus it was not clear whether YOT young people fitted the criteria or threshold to receive specialist treatment from mental health professionals.

\subsection{The resolution of tensions and the impact of austerity}

However, overall, while respondents talked extensively about the tensions in YOT partnerships in relation to the 'resource', 'participation' and 'quality of life' issues facing the young people that they worked with, it was generally acknowledged that most of these tensions were operational and had already considerably improved in recent years through better respect, communication and cultural understanding between YOTs and their partners. Indeed, most agreed that their partnership work was no longer 'a battleground' (YOT partnership stakeholder 29) but, as stated in the inspection report earlier, had become 'a key strength' (Criminal Justice Joint Inspection, 2011:37).

Similarly public spending cuts were not seen to pose insurmountable problems. This may be because at the time of this research these cuts were only just beginning to bite. Respondents could only talk very generally as to how they expected them to impact. Some speculated that the cuts would lead to 'absolutely mammoth changes' (YOT partnership stakeholder 28) with a dramatic decline in staffing levels and the quality of front line services. Others felt that YOT young people would be hardest hit because, as one respondent commented, 'it's the most vulnerable groups that will experience the cuts most negatively and that's creating problems for the future' (YOT partnership stakeholder 23). It was also expected, as predicted by Hollingsworth (2012), that the cuts would be accompanied by pressure to shift the focus even further away from concerns about young people's welfare towards correcting criminogenic attitudes and behaviour. But the overall feeling amongst interviewees was that so far the cuts 
"This is a final author's draft of a paper submitted for publication in International Journal of Law, Crime and Justice 2016 DOI:

http://dx.doi.org/10.1016/j.ijlcj.2015.11.001

had been managed rationally so that their potentially negative impact had been minimised. Several commented that they were not aware of compulsory redundancies only natural wastage. One respondent summed up this early optimism about the effects of the cuts as follows:

“...I think what they've done is to reorganize, reorganize and reorganize but I haven't seen any savage cuts to front line services...They've got rid of a whole raft of management but on the front line social workers are doing their job; they might be working under a slightly different structure but they're still there pretty much the same." (YOT partnership stakeholder 30)

\section{The survival and repackaging of welfare}

Despite concerns, it seems evident from this research that the pervasive effects of the audit and performance management culture and the threats posed by public spending cuts in youth justice have been overstated. These findings have been reiterated by many other researchers (Briggs, 2013; Field, 2007; Phoenix, 2009). An actuarial risk mentality undoubtedly influenced the professional context in which respondents worked with young people who offend, but a commitment to protecting their welfare nevertheless remained in the forefront of their thinking.

As one manager commented:

"...I've got a very passionate, dedicated team. They really believe in getting young people back on track and they work with them holistically." (YOT partnership stakeholder 14)

\subsection{The problematisation of welfare}

During the interviews, YOT practitioners expounded with great compassion and understanding about the entrenched personal and social problems experienced by the young people they worked with. This included the prolific range of difficulties arising from damaged family relationships, disaffection from school, restricted employment prospects and chaotic lifestyles already identified by previous research (see Jacobson et al., 2010). Mental health difficulties were seen as particularly intractable because they involved an amorphous mix of anxiety and depression not recognized as diagnosable psychiatric illnesses by mainstream child and adolescent mental health agencies, and so in their view not amenable to treatment. But overall, the majority of respondents stressed that while there had been a substantial rise in the 
"This is a final author's draft of a paper submitted for publication in International Journal of Law, Crime and Justice 2016 DOI:

http://dx.doi.org/10.1016/j.ijlcj.2015.11.001

numbers of young people diverted from the youth justice system, those that were still being prosecuted were displaying a disturbing increase in the complexity of their problems.

The child-friendly, welfare-orientated ethos of the 'every child matters' agenda (Department for Education and Skills, 2003) and the recommendations of the Munro Review on safeguarding and protecting children (Department for Education, 2011) were well ensconced into respondent's working practices. The main issue of at times heated debate was not whether young people who offend should be receiving the same kind of welfare support as 'other' vulnerable children, but who should be providing it. One group of respondents felt that welfare support should be provided by the YOT to compensate for the failings of other social service providers. Those in favour of keeping welfare work in the YOT argued like the following respondent:

"... if we want our young person to get additional services and support we need to be offering them and that should really be part of our role.....if I don't do it no-one else will." (YOT partnership stakeholder 2)

However, there was also a strong feeling amongst other respondents that the YOT should not be seen as a 'dumping ground' for problem children and that young people's welfare difficulties should rightly be the responsibility of mainstream social support agencies. This opinion is illustrated by the worker who commented:

"... we're quite clear that if the problem is around offending that's what we deal with...if it's bigger welfare issues that's where we'd expect children's services or other agencies to get involved really." (YOT partnership stakeholder 19)

\subsection{The criminalisation of welfare through the conflation of need with risk of offending}

The YOT partnerships in this research were undoubtedly imbued with a welfarist way of thinking and set of practices. But it was a 'repackaged' vision of welfare that blended together need and risk to create novel assemblages of 'risk/need management' (Hannah-Moffat and Maurutto, 2012: 206 and 215). Several research studies have also found that the emphasis on actuarial probability in the audit culture transforms the way in which YOT partnerships interpret and address the welfare needs of young people who offend (Field and Nelken, 2010; Goddard, 2012; Phoenix and Kelly, 2013). The 'criminogenic' and 'dynamic' properties of needs, or the extent to which they contribute to offending and are responsive to change become the crucial 
"This is a final author's draft of a paper submitted for publication in International Journal of Law, Crime and Justice 2016 DOI:

http://dx.doi.org/10.1016/j.ijlcj.2015.11.001

factors in assessment and intervention. ${ }^{7}$ Social justice concerns are of limited relevance. The choice of targets and performance indicators in YOT inspection reports, which are based on the assumption that young people's risk of reoffending will miraculously disappear by addressing the social risks attached to family breakdown, educational underachievement, substance misuse and mental illness, clearly illustrate how this dynamic combination of need and risk is understood (see Criminal Justice Joint Inspection, 2013).

But the point is more insightfully explained by one interviewee who responded when asked why most of the performance indicators in YOT inspections centred on addressing criminality rather than social welfare:

"...it's not that they don't pay attention to social factors but the way in which they're framed...yes, they did take them into account in their assessment of how well a case was managed, but only in the utilitarian sense that if you address social factors it'll have a kind of knock on effect on the criminal factors. So you're not looking at the social factors because they're children. It's looking at how you can use them to reduce offending." (YOT partnership stakeholder 15)

In general respondents understood the conflation of 'need' and 'risk' as finding a balance between correcting shortcomings in young people's criminogenic attitudes and behaviour and resolving wider welfare problems or, as one respondent commented, 'it's a bit of a mish mash of both things really' in order to prevent reoffending (YOT partnership stakeholder 23). However, there were differences of opinion among respondents as to whether welfare or correctionalism should be the primary consideration in this balancing act, with some tipping the balance towards welfare:

“...I can't split the two anymore. I think that children offend when they're unhappy which is when their welfare needs are not being met...but I think it's largely about welfare." (YOT partnership stakeholder 7)

Meanwhile others, like the respondent below, were more inclined to emphasise correctionalism:

“...most people would see the young person in a holistic way and see that you can't just work on the offending behaviour and you're doing all sorts of things...but it's probably fair to say that people focus more on offending." (YOT partnership stakeholder 6)

\footnotetext{
${ }^{7}$ This may change when AssetPlus is implemented because it suggests that welfare factors should be assessed in their own right independent of their association with risk of reoffending (Baker, 2014).
} 
"This is a final author's draft of a paper submitted for publication in International Journal of Law, Crime and Justice 2016 DOI:

http://dx.doi.org/10.1016/j.ijlcj.2015.11.001

\section{The individualisation and dematerialisation of welfare needs}

The positive outcome of the mixing together of need with risk of reoffending is that attention is drawn to the welfare difficulties facing young people who offend. But, because these problems are constituted somewhat restrictively around criminogenic and dynamic factors, their causes tend to be individualised or blamed on personal shortcomings in young people's anti-social attitudes, thinking processes and interpersonal skills. The broader societal limitations imposed by excessive levels of socio-economic disadvantage that aggravate young people's personal and social difficulties and limit their choices are seldom considered achievable targets for change (Kemshall, 2008). In this research the problematic effects of the individualisation and dematerialisation of need are particularly exemplified by the views of YOT partnership stakeholders on the causes of and solutions to the employment difficulties experienced by young people who offend.

\subsection{The problematisation of employment difficulties}

YOT professionals guided by Farrington's (2000) 'risk factor prevention paradigm' are led to believe that sorting out young people's employment difficulties and supporting them to find a job will significantly reduce their likelihood of reoffending. ${ }^{8}$ They are also in firm agreement that the shrinkage of the youth labour market during the recent economic recession has had a particularly negative effect on the chances of their target group achieving this goal. Voicing the views of several respondents, one worker reflected:

"...there are very few opportunities for children with this recession and high unemployment and our children are disadvantaged because they've got a criminal record." (YOT partnership stakeholder 30)

But despite awareness of such structural constraints, when asked about the main cause of young people's poor employment prospects most respondents nevertheless still stressed shortcomings in their attitudes, motivation, time-management and aspirations. One worker captured this viewpoint as follows:

\footnotetext{
${ }^{8}$ But this may be a fallacy because as pointed out by Ferguson (2013) the current high level of unemployment has been accompanied by a significant drop in youth crime. This challenges the research guiding the risk factor prevention paradigm.
} 
"This is a final author's draft of a paper submitted for publication in International Journal of Law, Crime and Justice 2016 DOI:

http://dx.doi.org/10.1016/j.ijlcj.2015.11.001

"...it's to do with the kids a lot of time.....I was working with this young person who was NEET (not in education, employment or training) and he was saying he was interested in building. A building opportunity came up...a fortnight of building experience, all paid for...loads of experience and out of that could be a springboard to other stuff......'m talking to him about it and he just didn't wanna do it. So I said 'why not' and he said 'I just can't be bothered'. I couldn't motivate him, he just couldn't be bothered." (YOT partnership stakeholder 5)

Beyond personal deficits, respondents were also concerned about young people's general lack of employability skills, particularly relevant educational qualifications. But social or 'soft' skills were seen to be equally important, because as one interviewee reflected:

"...Getting jobs for the young people that we work with are very hard because they don't have the social skills to get through an interview and they tend to be quite limited in what they think they want to do. We have quite a lot of appointments that aren't attended, quite often they'll have had problems in school or they've got communication problems or emotional difficulties - sustaining a full time job is really difficult for them." (YOT partnership stakeholder 21)

'Parenting' was also seen to be a 'massive bugbear' (YOT partnership stakeholder 20), with many respondents commenting that significant responsibility for employment difficulties rested on the failure of parents to provide appropriate guidance.

Educational training courses to correct shortcomings in young people's motivation to work and employability skills and make them 'job-ready' were upheld by the majority of interviewees as the best way to resolve unemployment. This was despite expressing disquiet about the quality of such training and scepticism that it was likely to lead to a job. But the core concern of respondents, as seen below, was ensuring that these courses made greater efforts to engage with YOT young people:

"...practitioners have gripes about the fact that sometimes the training providers don't do much to try to hang on to our young people, because they are difficult. If you ask them to do something they might tell you to 'fxxx off', they have very short attention spans, lots of personal issues that they bring in and they're very unreliable......so I think my impression of a lot of private training providers is that they would prefer to fill their books with nice kids rather than with our kids that are gonna be a pain in the bum ..." (YOT partnership stakeholder 13) 
"This is a final author's draft of a paper submitted for publication in International Journal of Law, Crime and Justice 2016 DOI:

http://dx.doi.org/10.1016/j.ijlcj.2015.11.001

The belief of YOT professionals in employability skills training as a solution to young people's employment difficulties echoes Kramer et al's. (2013) research in the USA which found that correctional officers unconsciously used these programmes to convey to young prisoners the neoliberal message that jobs were available if they actively took responsibility to seek them out. During this indoctrination process young prisoners were responsibilised into the neoliberal work ethic in which was embedded the implicit message that through their individual choices and actions they could overcome structural constraints. In reality, Kramer et al. (2013: 552) conclude, these young people were simply disciplined to conform to "post-Fordist labor conditions' by being encouraged to accept any job no matter how unsustainable.

\subsection{Reinforcing socio-economic disadvantage}

So why is the individualisation and dematerialisation of the employment needs of young people who offend problematic, and why does it reduce the chance that their needs will be met? According to some research, it is global economic restructuring and the consequent destruction of the youth labour market and not poor employability qualifications and skills which have made it so difficult for young people to find employment (Ferguson, 2013). The seriousness of the problem can be seen from the UK situation where $31.2 \%$ of economically active 16 to 17 year olds were unemployed between October to December 2014 (Office for National Statistics, 2015). Contrary to popular opinion most young people are very motivated to seek work and have realistic expectations about what is available, but those who do manage to get work often end up in the low paid, insecure, part-time employment sector (Reid and Cominetti, 2013). While the government has sought to create more jobs, Lee et al. (2012:44) argue that their policies have been poorly co-ordinated and 'insufficient to address the scale of the problem'. Similarly employability skills training schemes which remain the most favoured policy response are not a solution as few young people who complete them actually end up in work (Department for Work and Pensions, 2014).

The difficulty of finding employment for disadvantaged young people with limited qualifications and skills is particularly challenging (Tunstall et al., 2012). The experience of young people leaving custody is a case in point. Research from HM Inspectorate of Prisons (Prime, 2014) reported that young people in custody were highly motivated to find work upon release, but were let down by the poor quality vocational training programmes available in custody, which were seen by almost a half of participants to be unhelpful. This was reinforced by other 
"This is a final author's draft of a paper submitted for publication in International Journal of Law, Crime and Justice 2016 DOI:

http://dx.doi.org/10.1016/j.ijlcj.2015.11.001

research (HM Inspection of Prisons, 2011) which found that only a small percentage of young people had a job to go to on release from custody and that those jobs that were available were unsustainable as most were casual, short term and underpaid. Overall the limited job prospects of young people who offend does little to encourage them to stop offending, and the dematerialisation of the problem simply reinforces the feelings of stigmatisation and social exclusion already attached to their criminal identity.

\section{Conclusion: towards a 'child friendly' rights-based approach}

In conclusion it is worth reflecting on how a 'child friendly' rights-based approach, which draws on International and European human rights standards, could be developed in law, policy and practice to protect the welfare or 'best interests' of young people who offend. ${ }^{9}$ Numerous rights organisations such as the Children's Rights Alliance (CRAE), the Howard League and the International Juvenile Justice Observatory (IJJO) have campaigned for years for such an approach to be implemented. But rights-based perspectives have been subject to extensive scepticism, with critics highlighting their limitations and dangers. Muncie and Goldson (2013: 346) argue that the 1989 UNCRC has been 'the most ratified of all international human rights instruments' but also 'the most violated' and essentially has 'no teeth' as it is not legally enforceable. Further, Goldson and Kilkelly (2013: 345) 'challenge the legitimacy' of rightsbased approaches. They argue, echoing the abolitionist stance of Nils Christie (1982), that the emphasis should be on questioning the legitimacy of the use of imprisonment for young offenders, rather than simply seeking to reform it. For Goldson (2013: 123), the focus should be on raising the age of criminal responsibility (which currently stands at 10 in England and Wales) to keep young people who offend out of the youth justice system where their 'social needs are criminalised', and instead deal with them through the child care system where they can be treated as 'children first'.

Undoubtedly the above criticisms are justified. Many of the proposals produced from campaigning rights organizations have been vague and impossible to enforce. For example, a report commissioned by the IJJO (Moore, 2013) is entitled 'Improving Youth Justice Systems During A Time of Economic Crisis', but does little more than reiterate the same old recommendations about preventing youth crime, diverting young people from prosecution and custody, and the effectiveness of community sanctions. No enforcement strategies are

\footnotetext{
${ }^{9}$ I have pursued this position in previous articles (see Gray, 2007, 2011).
} 
"This is a final author's draft of a paper submitted for publication in International Journal of Law, Crime and Justice 2016 DOI:

http://dx.doi.org/10.1016/j.ijlcj.2015.11.001

suggested to give these policies legal clout. Nevertheless, several of these organizations have made a significant contribution to protecting young people's rights in the youth justice system (such as the Howard League campaigns to stop the use of strip searching and restraints). ${ }^{10}$ Hence, despite the limitations, it can be argued that a rights-based agenda does provide a powerful starting point to protect the social rights of young people in youth justice proceedings.

The first issue to be considered in advancing a rights-based approach is that, as Hollingsworth (2013: 1048) points out, there is a 'theory gap' in conceptualising children as having unique rights over and above their fundamental human rights. Hollingsworth tries to fill this gap by proposing a theoretical account of 'children's rights' in which she argues that children possess 'foundational' rights. These protect 'assets', such as the right to a basic standard of living, health and education, which will enable children to become 'fully autonomous' adults. The concept of 'foundational' rights places a responsibility on the state to protect children's rights and to nurture their 'assets' so that they can mature into adulthood. This in turn implies that the youth justice system must operate in such a way that it supports, and certainly does not harm, the development of 'assets' in compliance with 'foundational' rights. Hollingsworth mainly applies this analysis to advocate for an increase in the age of criminal responsibility, as per Goldson (2013), and to protect the resettlement rights of young people leaving custody. But it can equally be applied to the way young people are dealt with at every stage of the youth justice process.

The 'Children and Young People First' strategy in Wales (Welsh Government and Youth Justice Board, 2014) seems to offer a good example of a government attempt to protect the foundational rights of young people. The strategy is guided by a children's rights agenda which places the child's wellbeing or welfare at the heart of youth justice policy and practice and reflects the efforts of the Welsh Assembly working alongside the Youth Justice Board to engage with the 1989 UNCRC. The approach appears to have been met with some success as there is evidence of significant reductions in both the number of first time entrants (FTEs) to the youth justice system and those entering youth custody in Wales. The Swansea Bureau has received widespread acclaim as an exemplary model of the approach in action in a diversionary project (Haines et al., 2013). The Welsh government's attempt to adopt a children's rights perspective is insightful and admirable. But it is still early days in the development of the approach, and the

\footnotetext{
${ }^{10}$ See Howard League Campaigns Justice for Children and Young People. Available at: http://www.howardleague.org/key-issues/ (last accessed 30.07.15.).
} 
"This is a final author's draft of a paper submitted for publication in International Journal of Law, Crime and Justice 2016 DOI:

http://dx.doi.org/10.1016/j.ijlcj.2015.11.001

fall in FTEs and the number of young people receiving custodial sentences has also been evident throughout the whole of England and Wales in recent years, resulting in considerable debate about the extent to which the outcome in Wales can be attributed to deliberate policy decisions, demographic changes or a drop in the rate of youth crime (Smith, 2014a; Bateman, 2012).

Much of the 'Children and Young People First' strategy in Wales is directed at improving youth justice 'processes' to ensure that they are child-friendly and facilitate active 'participation' and 'engagement' by young people and their families. Another important feature of the strategy has been to address the type of tensions raised by YOT professionals in this research and wider national studies by setting up a systematic, comprehensive policy to improve 'access to', 'delivery of' and 'engagement with' youth justice and social services through better partnership working. But the 'outcomes' of these processes and how they will be monitored remain vague. While there is a lot of talk in the policy documents of 'entitlements' and how 'services are held to account for addressing the needs of young people' (Welsh Government and Youth Justice Board, 2014: 4), it is not specified how this will take place or how entitlements will be legally enforceable. Indeed the same discourses about the importance of 'participation' and 'engagement' in compliance with article 12 of the UNCRC to give young people a voice are already evident in the practices of many English YOTs (Smith, 2014b), as is the stress on developing effective partnerships between YOTs and other social services in policies produced by the Youth Justice Board (2013) in regard to the English youth justice system. Hence the need to define entitlements more precisely and set up monitoring arrangements which are enforceable in law would still seem to be universal to all youth justice jurisdictions in the UK.

As pointed out earlier, Hollingsworth (2013) provides a cogent argument that young people who offend nevertheless possess 'foundational rights' that are essential to enable them to develop into independent adults. The Welsh youth justice strategy has framed these rights as a set of universal entitlements to meet the wider social needs, not just the criminogenic needs, of young people in conflict with the law who are viewed as 'children first, offenders second' (Welsh Government and Youth Justice Board, 2014: 4). Conceptualising social needs in terms of universal entitlements should lead to their decriminalisation by placing responsibility for their fulfilment on policy makers and practitioners rather than blaming their existence on the perceived personal deficits of young people who offend and their families. This should encourage youth justice bodies, such as the Youth Justice Board and YOTs, to pay closer 
"This is a final author's draft of a paper submitted for publication in International Journal of Law, Crime and Justice 2016 DOI:

http://dx.doi.org/10.1016/j.ijlcj.2015.11.001

attention to the quality of services and the success of outcomes from the young person's point of view rather than simply facilitating access, engagement and participation in order to reduce reoffending.

Levitas et al's. (2007) matrix for measuring social disadvantage offers a useful framework to draw up a more precise and detailed set of national indicators of entitlements in the three areas of 'resources', for example supportive family/interpersonal environment, 'participation', for example education that develops the fullest potential and sustainable employment, and 'quality of life', for example the highest attainable mental health care, that would address the extreme levels of social deprivation experienced by young people under the supervision of YOTs. Equally the concept of entitlements would have to be grounded in what Fraser (2003) defines as a 'transformative' or structurally informed and socially just interpretation of needs to avoid the pitfalls of individualisation and dematerialisation raised earlier. Finally this framework of entitlements would have to be made legally enforceable if it were to have any concrete and lasting impact on outcomes. In this respect some of the recommendations of the Carlile Inquiry (2014: 56) appear to be on the right track. These include 'the piloting of a problem-solving approach' in the youth court with powers to ensure that the welfare needs of young people who offend are thoroughly investigated and that social welfare services are held to legal account in meeting these needs. Such recommendations draw on the research evidence on Family Group Conferences in New Zealand (Lynch, 2009) and drug treatment courts in Canada (Moore, 2011) which claim some success in addressing the social welfare difficulties of their respective target groups. ${ }^{11}$ Realistically, in the short-term the ability to translate Carlile's (2014) recommendations into law, and the policy and practice of youth justice, ${ }^{12}$ would take a far more powerful and progressive political will than has been evident in the penal climate of recent years.

\section{Acknowledgements}

This work was supported by a Strategic Research Grant from Plymouth University School of Law.

With thanks to Mike Ives for assistance with the thematic data analysis using NVivo.

\footnotetext{
${ }^{11}$ This success comes at a price as critics highlight how welfare support is often backed up by surveillance, control and punitive sanctions (Moore, 2011).

${ }_{12}$ But some YOTs are already experimenting with a problem solving approach (see Ward and Warkel, 2015).
} 
"This is a final author's draft of a paper submitted for publication in International Journal of Law, Crime and Justice 2016 DOI:

http://dx.doi.org/10.1016/j.ijlcj.2015.11.001

\section{References}

Baker, K., 2014. AssetPlus Rationale, revised edition. Youth Justice Board, London.

Berelowitz, S., 2011. 'I Think I Must Have Been Born Bad'. Emotional Wellbeing and Mental Health of Children and Young People in the Youth Justice System. Office of the Children's Commissioner, London.

Bateman, T., 2012. Who pulled the plug? Towards an explanation of the fall in child imprisonment in England and Wales. Youth Justice 12(1), 36-52.

Briggs, D.B., 2013. Conceptualising risk and need: The rise of actuarialism and the death of welfare? Practitioner assessment and intervention in the youth offending service. Youth Justice 13(1), 17-30.

Care Quality Commission and HMI Probation, 2011. Re: Actions. A Third Review of Healthcare in the Community for Young People Who Offend. Care Quality Commission, London.

Carlile, Lord, 2014. Independent Parliamentarians' Inquiry into the Operation and Effectiveness of the Youth Court. Michael Sieff Foundation, London.

Centre for Social Justice, 2012. Rules of Engagement. Changing the Heart of Youth Justice. Centre for Social Justice, London.

Children's Rights Alliance (CRAE), 2014. State of Children's Rights in England 2014. Children's Rights Alliance, London.

Christie, N., 1982. Limits to Pain. Martin Robertson, Oxford.

Committee on the Rights of the Child (CRC), 2008. Concluding Observations: United Kingdom of Great Britain and Northern Ireland. $\mathrm{CRC} / \mathrm{C} / \mathrm{GBR} / \mathrm{CO} / 43$ October. United Nations, Geneva.

Council of Europe, 2010. Guidelines of the Committee of Ministers of the Council of Europe on Child Friendly Justice. Council of Europe, Strasbourg.

Criminal Justice Joint Inspection, 2011. A Joint Inspection of Offending Behaviour, Health and Education, Training and Employment Interventions in Youth Offending Work in England and Wales. HM Inspectorate of Probation, Manchester.

Criminal Justice Joint Inspection, 2012. Looked After Children: An Inspection of the Work of Youth Offending Teams with Children and Young People Who are Looked After and Placed Away from Home. HM Inspectorate of Probation, Manchester.

Criminal Justice Joint Inspection, 2013. Core Case Inspection of Youth Offending Work in England and Wales: Aggregate Report of the Findings from HMI Probation's Core Case Inspection Programme 2009-2012. HM Inspectorate of Probation, Manchester.

Deloitte, 2015. Youth Offending Team Stocktake. Ministry of Justice, London.

Department for Education and Skills, 2003. Every Child Matters: Change for Children. The Stationery Office, London.

Department for Education, 2011. The Munro Review of Child Protection: Final Report - A Child Centred System. The Stationery Office, London.

Department for Work and Pensions, 2014. Work Programme Statistical Summary: Data to September 2014. Available at: http://statistics.dwp.gov.uk/asd/index.php?page=wp (last accessed 30.07.15.).

Farrington, D., 2000. Explaining and preventing crime: the globalisation of knowledge. Criminology 38(1), 1-24.

Ferguson, R., 2013. Risk, responsibilities and rights: reassessing the 'economic causes of crime' thesis in a recession. Youth Justice 13(1), 31-56.

Field, S., 2007. Practice cultures and the 'new' youth justice in England and Wales. British Journal of Criminology 47(2), 311-330. 
"This is a final author's draft of a paper submitted for publication in International Journal of Law, Crime and Justice 2016 DOI:

http://dx.doi.org/10.1016/j.ijlcj.2015.11.001

Field, S., Nelken, D., 2010. Reading and writing youth justice in Italy and (England and) Wales. Punishment and Society 12(3), 287-308.

Fraser, N., 2003. Social justice in the age of identity politics: redistribution, recognition and participation. In: Fraser, N., Honneth, A. (Eds.), Redistribution or Recognition? A PoliticalPhilosophical Exchange. Verso, London.

Goddard, T., 2012. Post-welfarist risk managers? Risk, crime prevention and the responsibilization of community-based organisations. Theoretical Criminology 16(3), 346363.

Goldson, B., 2010. The sleep of (criminological) reason: knowledge-policy rupture and New Labour's youth justice legacy. Criminology and Criminal Justice 10(1), 155-178.

Goldson, B., 2013. 'Unsafe, unjust and harmful to wider society': grounds for raising the minimum age of criminal responsibility in England and Wales. Youth Justice 13(2), 111-130.

Goldson, B., Kilkelly, U., 2013. International human rights standards and child imprisonment: potentialities and limitations. International Journal of Children's Rights 21(2), 345-371.

Gray, P., 2007. Youth justice, social exclusion and the demise of social justice. Howard Journal of Criminal Justice 46(4), 401-416.

Gray, P., 2011. Youth custody, resettlement and the right to social justice. Youth Justice 11(3), 235-249.

Gray, P., 2013. Assemblages of penal governance, social justice and youth justice partnerships. Theoretical Criminology 17(4), 517-534.

Hannah-Moffat, K., Maurutto, P., 2012. Shifting and targeted forms of penal governance: bail, punishment and specialized courts. Theoretical Criminology 16(2), 201-219.

Haines, K., Case, S., Davies, K., Charles, A., 2013. The Swansea Bureau: A model of diversion from the youth justice system. International Journal of Law, Crime and Justice 41(2), 167187.

HM Government, 2008. Youth Crime Action Plan 2008. Youth Justice Board, London.

HM Inspectorate of Prisons, 2011. Resettlement Provision for Children and Young People: Accommodation and Education, Training and Employment. HM Inspectorate of Prisons, London.

Hollingsworth, K., 2012. Youth justice reform in the 'big society'. Journal of Social Welfare and Family Law 34(2), 245-259.

Hollingsworth, K., 2013. Theorising children's rights in youth justice: the significance of autonomy and foundational rights. The Modern Law Review 76(6), 1046-1069.

House of Commons Justice Committee (HCJC), 2013. Youth Justice. The Stationery Office Limited, London.

Jacobson, J., Bhardiva, B., Gyateng, T., Hunter, G., Hough, M., 2010. Punishing Disadvantage: A Profile of Children in Custody. Prison Reform Trust, London.

Kramer, R., Rajah, V., Sung, H., 2013. Neoliberal prisons and cognitive treatment: calibrating the subjectivity of incarcerated young men to economic inequalities. Theoretical Criminology 17(4), 535-556.

Kemshall, H., 2008. Risk, rights and justice: understanding and responding to youth risk. Youth Justice 8(1), 21-37.

Kilkelly, U., 2011. Measures of Deprivation of Liberty for Young Offenders: How to Enrich International Standards in Juvenile Justice and Promote Alternatives to Detention in Europe? International Juvenile Justice Observatory, Belgium.

Lee, N., Sissons, P., Balaram, B., Jones, K., Cominetti, N., 2012. Short-term Crisis - Long-term Problem?: Addressing the Youth Employment Challenge. The Work Foundation, London. 
"This is a final author's draft of a paper submitted for publication in International Journal of Law, Crime and Justice 2016 DOI:

http://dx.doi.org/10.1016/j.ijlcj.2015.11.001

Levitas, R., Pantazis, C., Fahmy, E., Gordon, D., Lloyd, E., Patsias, D., 2007. A MultiDimensional Analysis of Social Exclusion. Policy Press, Bristol.

Lynch, N., 2008. Youth justice in New Zealand: a children's rights perspective. Youth Justice 8(3), 215-228.

Ministry of Justice, 2015. Youth Justice Statistics 2013/14. Youth Justice Board and Ministry of Justice, London.

Ministry of Justice and Youth Justice Board, 2013. Modern Youth Offending Partnerships. Youth Justice Board, London.

Moore, D., 2011. The benevolent watch: therapeutic surveillance in drug treatment court. Theoretical Criminology 15(3), 255-268.

Moore, M., 2013. Save Money, Protect Society and Realise Youth Potential: Improving Youth Justice Systems During a Time of Economic Crisis. International Juvenile Justice Observatory, Belgium.

Muncie, J., 2011. Illusions of difference: comparative youth justice in the devolved United Kingdom. British Journal of Criminology 51(1), 40-57.

Muncie, J., 2015. Youth and Crime, fourth ed. Sage, London.

Muncie, J., Goldson, B., 2013. Youth justice: in a child's best interests? In: Simon, J., Sparks, R. (Eds.), The Sage Handbook of Punishment and Society. Sage, London.

National Audit Office, 2010. The Youth Justice System in England and Wales: Reducing Offending by Young People. The Stationery Office, London.

Office for National Statistics, 2015. Statistical Bulletin: UK Labour Market, February 2015. Office for National Statistics, London.

Parsloe, P., 1978. Juvenile Justice in England and the United States: The Balance of Needs and Rights. Routledge and Kegan Paul, London.

Phoenix, J., 2009. Beyond risk assessment: the return of repressive welfarism. In: Barry, M., McNeill, F. (Eds.), Youth Offending and Youth Justice. Jessica Kingsley Publishers,London.

Phoenix, J., Kelly, L., 2013. 'You have to do it for yourself'. Responsibilization in youth justice and young people's situated knowledge of youth justice practice. British Journal of Criminology 53(3), 419-437.

Prime, R., 2014. Children in Custody 2013-14: An Analysis of 12-18-Year-Old's Perceptions of Their Experience in Secure Training Centres and Young Offender Institutions. HM Inspectorate of Prisons and Youth Justice Board, London.

Reid, B., Cominetti, N., 2013. Youth Insight: The Voices of UK Young People on Their Experience of The World of Work, and Their Aspirations for the Future. The Work Foundation, London.

Soloman, E., Garside, R., 2008. Ten Years of Labour's Youth Justice Reforms: An Independent Audit. Centre for Crime and Justice Studies, London.

Smith, R., 2014a. Re-inventing diversion. Youth Justice 14(2), 109-121.

Smith, R., 2014b. Towards a 'welfare+rights' model in youth justice. Critical and Radical Social Work 2(3), 287-303.

Souhami, A., 2009. Doing youth justice: beyond boundaries?. In: Barry, M., McNeill, F. (Eds.), Youth Offending and Youth Justice. Jessica Kingsley Publishers, London.

Tunstall, R., Lupton, R., Green, A., Watmough, S., Bates, K., 2012. Disadvantaged Young People Looking for Work: A Job In Itself? Joseph Rowntree Foundation, York.

United Nations General Assembly, 1989. United Nations Convention on the Rights of the Child. United Nations, New York.

Youth Justice Board, 2010. A Review of YOTs and Children's Services' Interaction with Young Offenders and Young People at Risk. Youth Justice Board, London. 
"This is a final author's draft of a paper submitted for publication in International Journal of Law, Crime and Justice 2016 DOI:

http://dx.doi.org/10.1016/j.ijlcj.2015.11.001

Ward, J. and Warkel, K., 2015. Northampton Youth Offending Service Review Panel Evaluation. Centre for Social and Criminological Research, Middlesex University, London.

Welsh Government and Youth Justice Board, 2014. Children and Young People First. Welsh Government, Cardiff. 